Supplement of Geosci. Model Dev., 10, 827-841, 2017

http://www.geosci-model-dev.net/10/827/2017/

doi:10.5194/gmd-10-827-2017-supplement

(C) Author(s) 2017. CC Attribution 3.0 License.

(c) (i)

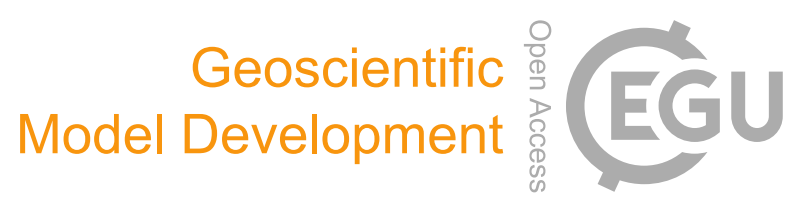

Supplement of

\title{
OZO v.1.0: software for solving a generalised omega equation and the Zwack-Okossi height tendency equation using WRF model output
}

Mika Rantanen et al.

Correspondence to: Mika Rantanen (mika.p.rantanen@helsinki.fi)

The copyright of individual parts of the supplement might differ from the CC-BY 3.0 licence. 
S1 Supplementary material

\section{S1.1 Forcing terms}
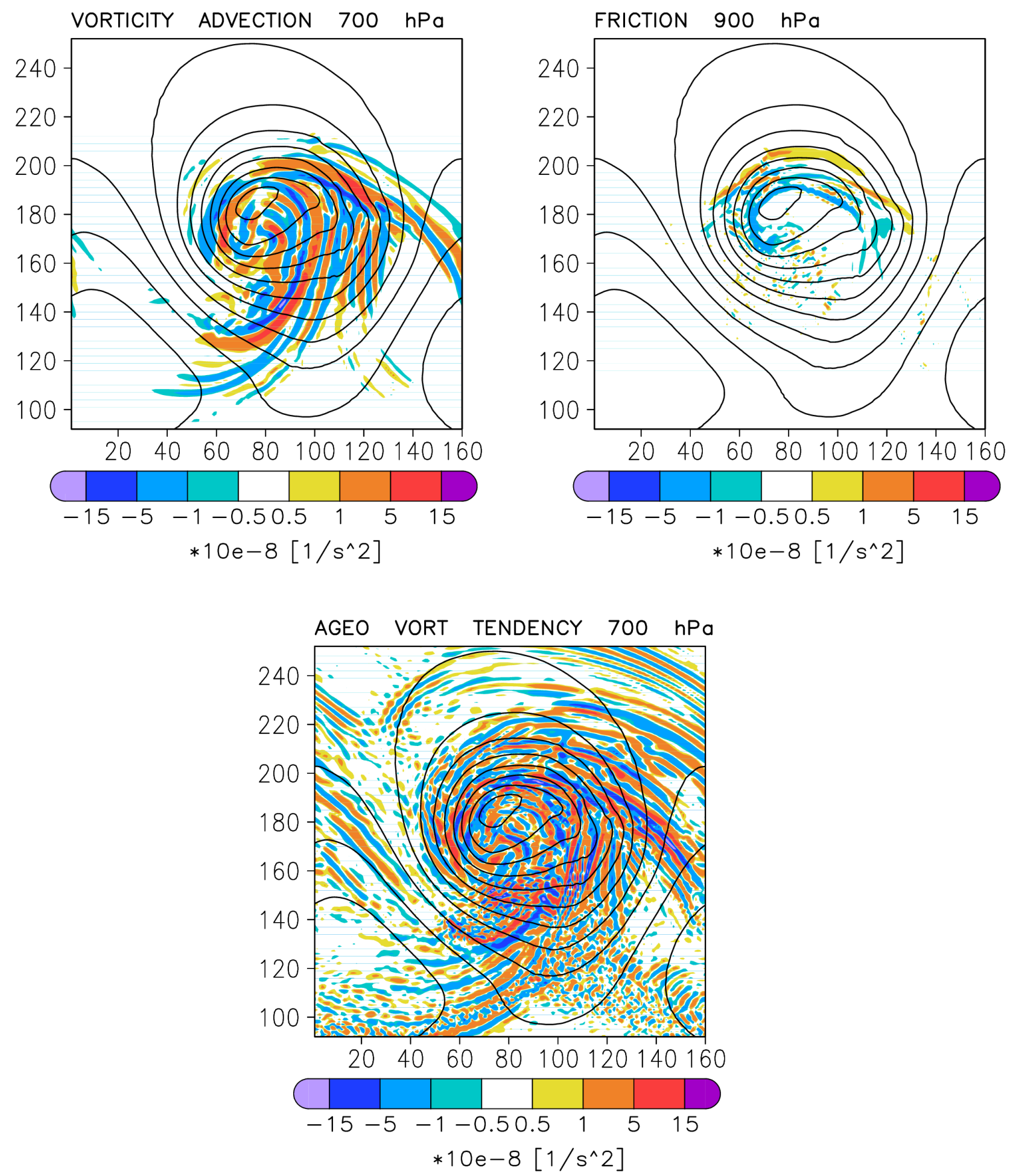

Figure S1: Vorticity advection $(-\mathbf{V} \cdot \nabla(\zeta+f))$, friction $(\mathbf{k} \cdot \nabla \times \mathbf{F})$ and ageostrophic vorticity tendency $(\partial \zeta a g / \partial t)$. Note that friction is at the $900 \mathrm{hPa}$ level but vorticity advection and ageostrophic vorticity tendency at $700 \mathrm{hPa}$. 
THERMAL ADVECTION $700 \mathrm{hPa}$

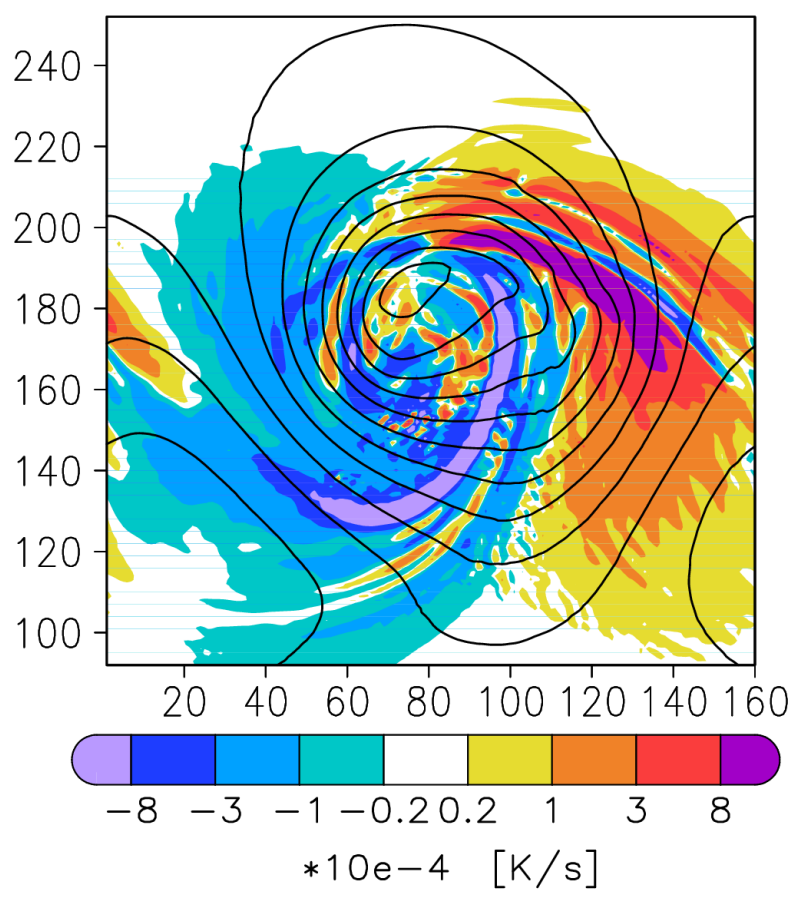

DIABATIC HEATING $700 \mathrm{hPa}$

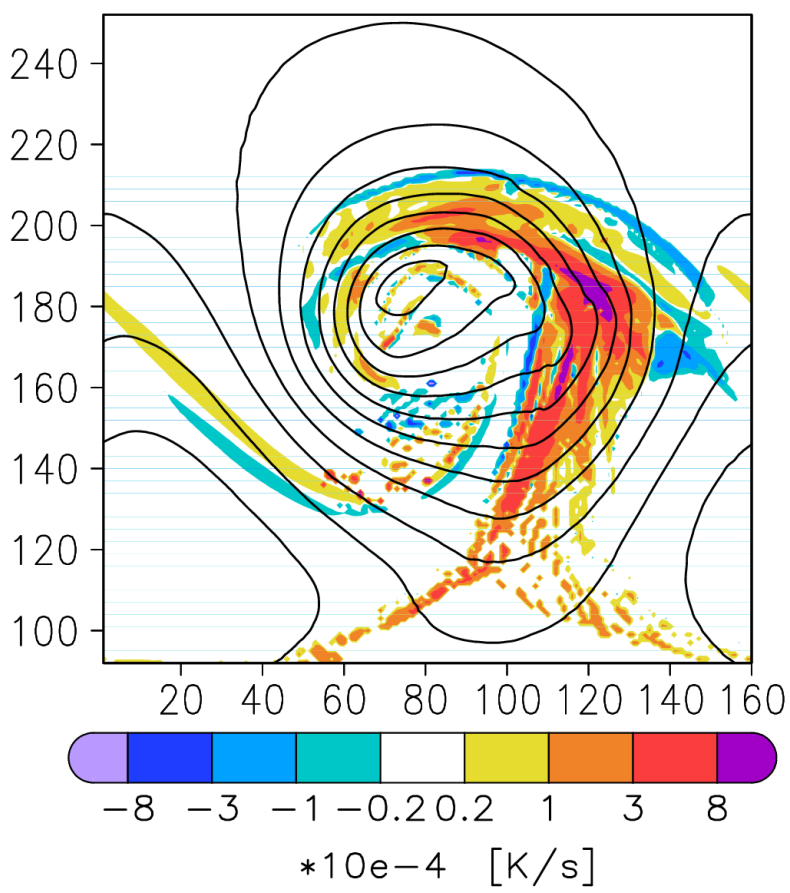

Figure S2: Thermal advection $(-\mathbf{V} \cdot \nabla T)$ and diabatic heating $(Q)$ at the $700 \mathrm{hPa}$ level.

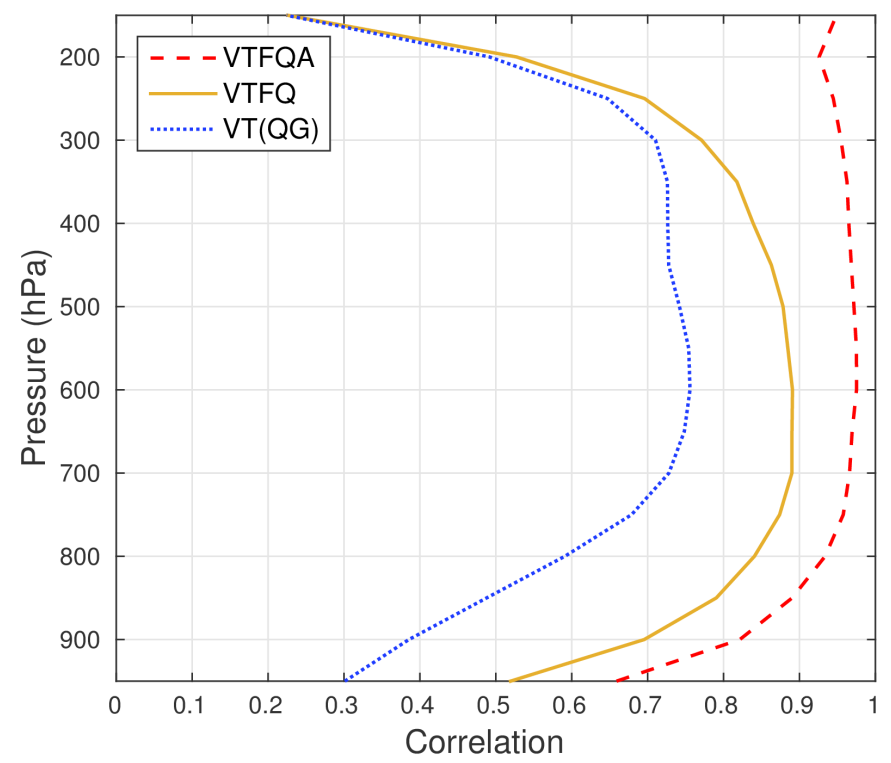

Figure S3: Correlation of the omega equation solutions with $\omega_{W R F}$ at $100 \mathrm{~km}$ grid spacing. $V T F Q A=\omega_{T O T}$, $V T F Q=\omega_{T O T}-\omega_{A}, V T(Q G)=\omega_{V(Q G)}+\omega_{T(Q G)}$.

\section{S1.2 Results at $100 \mathrm{~km}$ horizontal resolution}

Figures S3, S4 and S5 provide information on correlations and RMS values of vertical motions and height tendencies diagnosed with OZO from a $100 \mathrm{~km}$ horizontal resolution WRF simulation. The correlations for vertical motion (lines $V T F Q A, V T F Q$ and $V T(Q G)$ in Fig. S3 and Fig. 3) are slightly but systematically better at $100 \mathrm{~km}$ than at 25 $\mathrm{km}$ resolution. Higher resolution brings much more mesoscale detail in the simulated weather system, which tends to increase the discrepancy between $\omega_{T O T}$ and $\omega_{W R F}$, and thus reduce the correlation between the fields. These mesoscale features also increase the magnitude of the imbalance term and the other terms omitted in the quasi-geostrophic omega equation, thus deteriorating the correlation for the quasi-geostrophic solution at higher resolution.

As expected, the RMS amplitude of vertical motions is smaller at $100 \mathrm{~km}$ than $25 \mathrm{~km}$ resolution. In addition, there are some differences in the relative importance of the individual $\omega$ components. $\operatorname{RMS}\left(\omega_{T}\right)$ increases more than $\operatorname{RMS}\left(\omega_{V}\right)$ when the horizontal resolution is improved (see Section 6.2). The effect of latent heat release has also 
tendency to increase at higher resolution (Willison et al., 2013) and our results confirm that vertical motions induced by diabatic heating are strongly sensitive to the horizontal resolution, especially in the lower troposphere where shallow convection occurs (compare Fig. S4 to Fig. 4). In the lower troposphere, in particular, the imbalance term is also much larger at $25 \mathrm{~km}$ than $100 \mathrm{~km}$ resolution.

Figures S5 and 7 show that the error in height tendency fields grows as well when the resolution is improved, but this only leads to a marginal deterioration in the tropospheric correlation between the calculated and directly diagnosed height tendencies.

Figures S6, S7, S8 and S9 show the horizontal distributions of the diagnozed vertical motions and height tendencies at $100 \mathrm{~km}$ resolution, analogously to the corresponding results for the $25 \mathrm{~km}$ simulation in Figs. 1, 5, 6 and 8 . The basic features are largely the same but, as expected, there is much less small-scale detail in the results derived from the $100 \mathrm{~km}$ simulation.

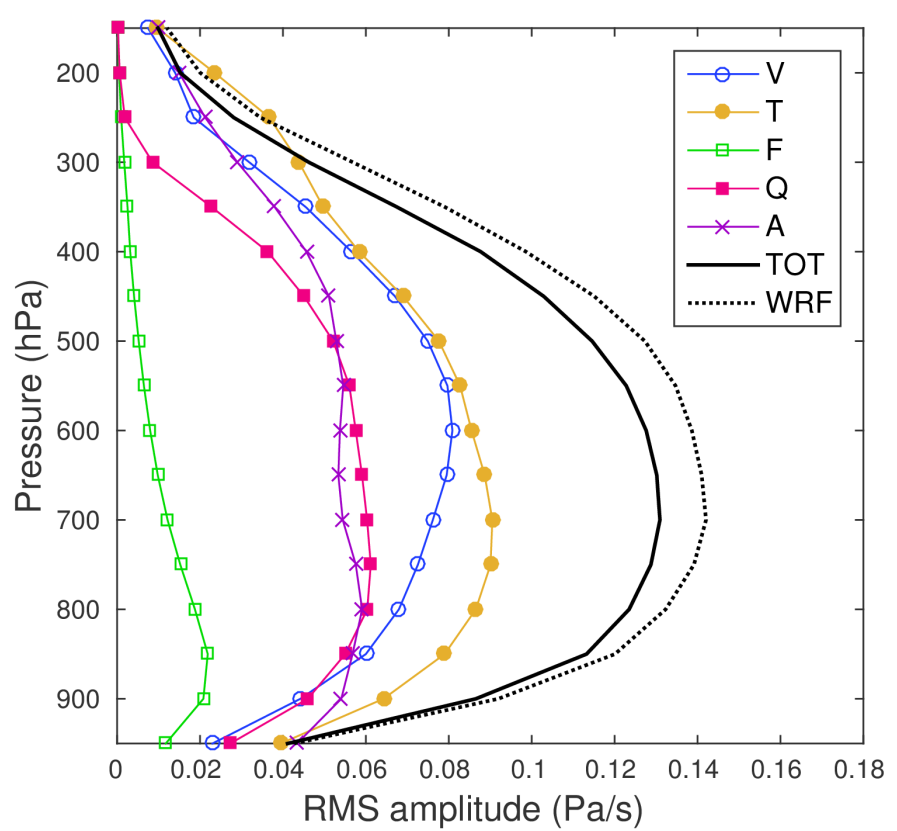

Figure S4: RMS amplitudes of $\omega_{W R F}, \omega_{T O T}$, and the individual $\omega$ components from Eq. 5 at $100 \mathrm{~km}$ grid spacing.
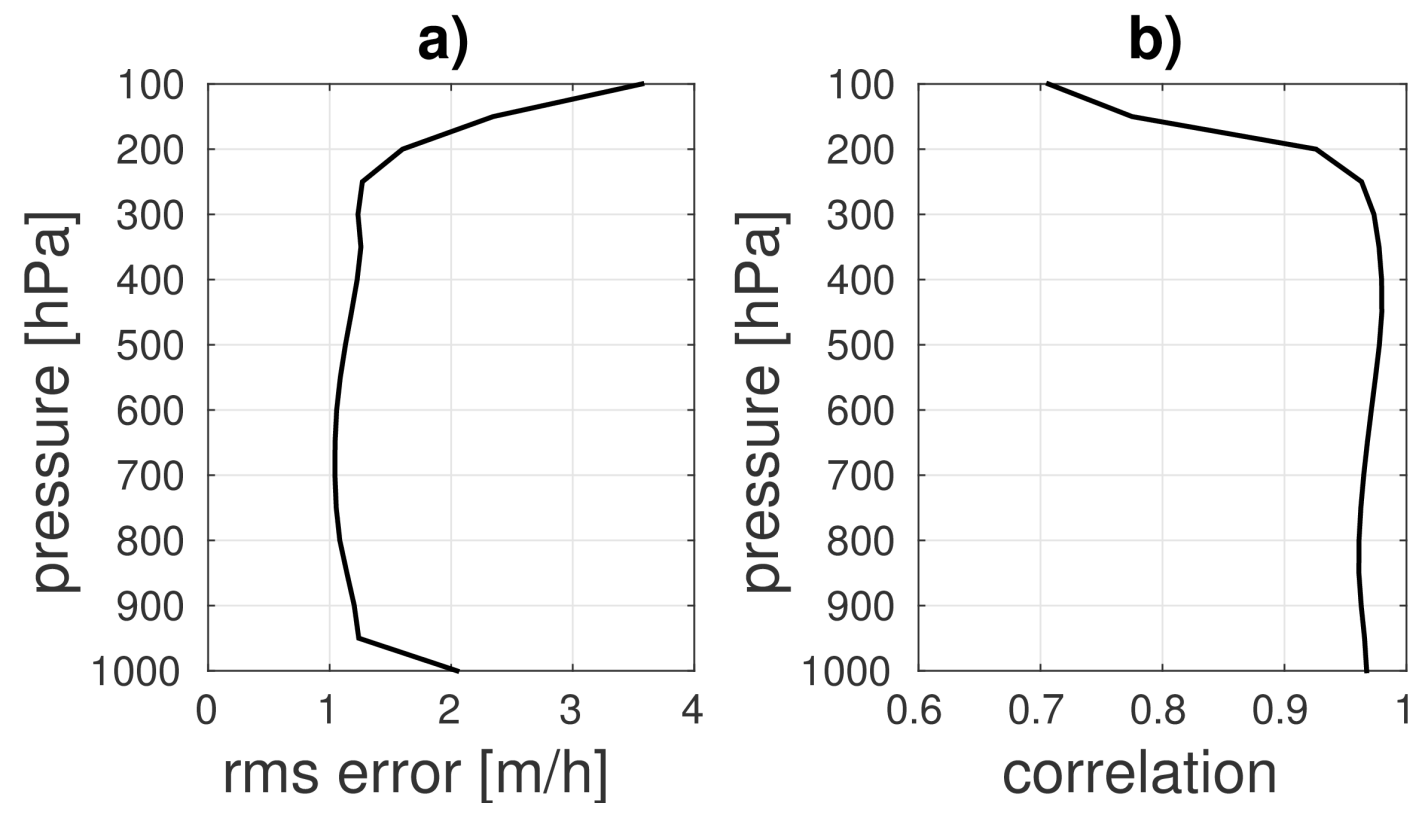

Figure S5: Time mean a) rms error and b) spatial correlation coefficient between calculated and WRF height tendency over the last 8 days of the 10-day simulation at $100 \mathrm{~km}$ grid spacing. 

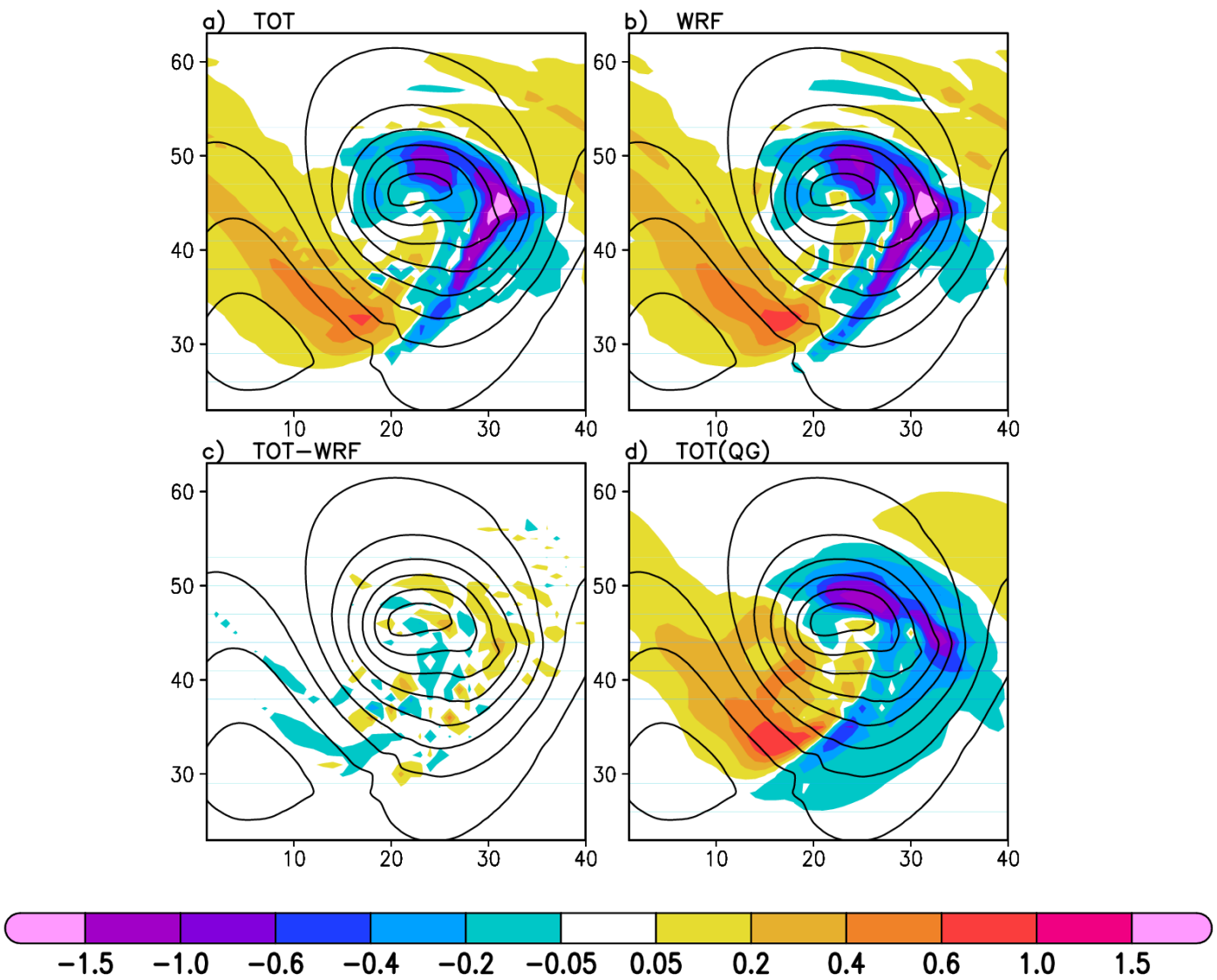

Figure S6: a) The sum of all $\omega$ components from Eq. (5) $\left(\omega_{T O T}\right)$, b) $\omega$ from WRF $\left(\omega_{W R F}\right)$, c) difference $\left(\omega_{T O T}-\omega_{W R F}\right)$ and d) solution of the QG omega equation $\left(\omega_{V(Q G)}+\omega_{T(Q G)}\right)$ at $700 \mathrm{hPa}$ level at time $118 \mathrm{~h}$, using $100 \mathrm{~km}$ grid spacing. Unit is $\mathrm{Pas}^{-1}$. Contours show geopotential height at $900 \mathrm{hPa}$ level with an interval of $50 \mathrm{~m}$. Labels on $\mathrm{x}$ - and $\mathrm{y}$-axes indicate grid point numbers. Note that the area covers only half of the model domain in the meridional direction. Compare with Fig. 1 in the main paper. 

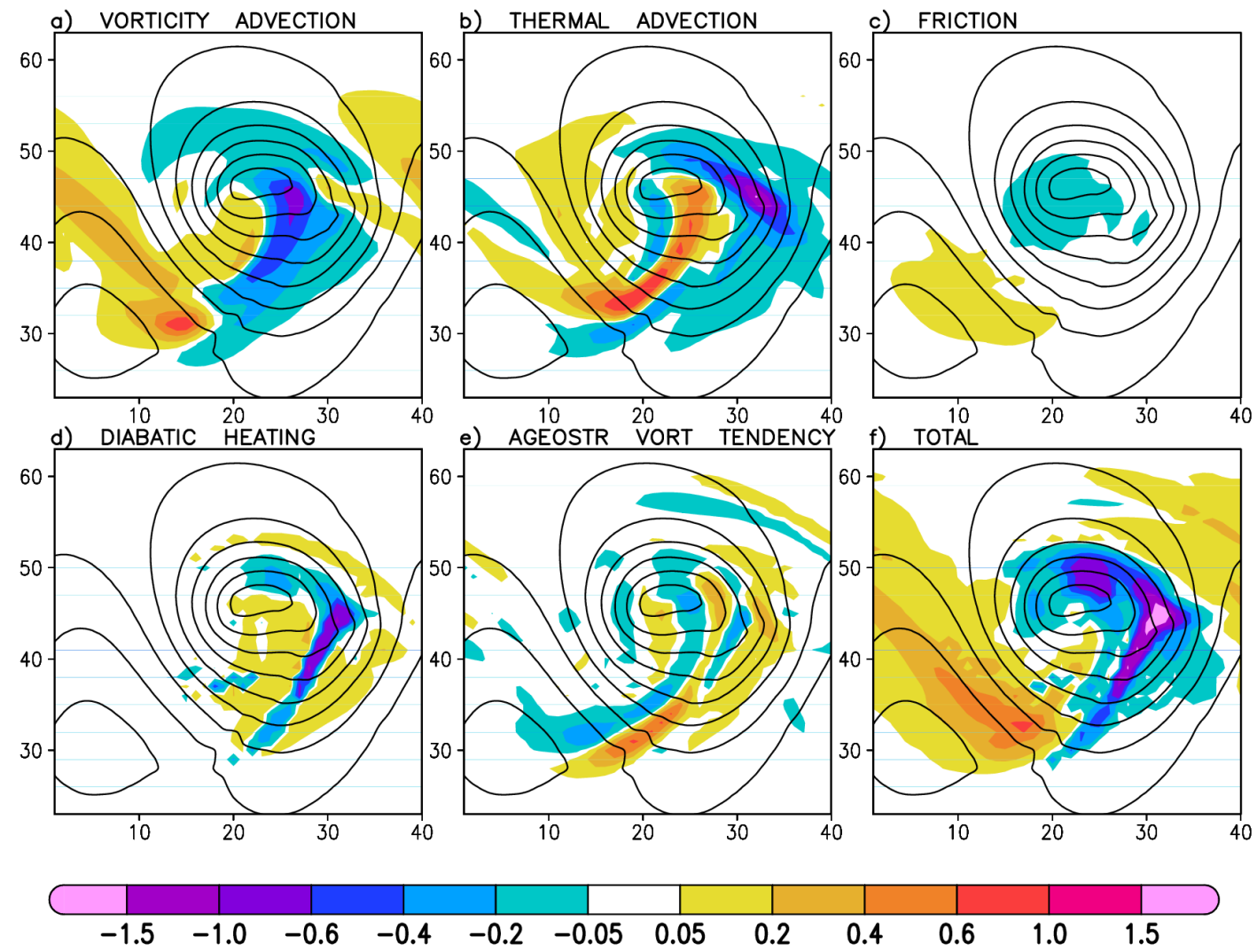

Figure S7: Vertical motions induced by individual forcing terms at level $700 \mathrm{hPa}$ at time $118 \mathrm{~h}$, using $100 \mathrm{~km}$ grid spacing. a) $\omega_{V}$, b) $\omega_{T}$, c) $\omega_{F}$, d) $\omega_{Q}$, e) $\omega_{A}$ and f) $\omega_{T O T}$. Unit is $P a s^{-1}$ and contour lines show $900 \mathrm{hPa}$ geopotential height with $50 \mathrm{~m}$ interval. Compare with Fig. 5 in the main paper.
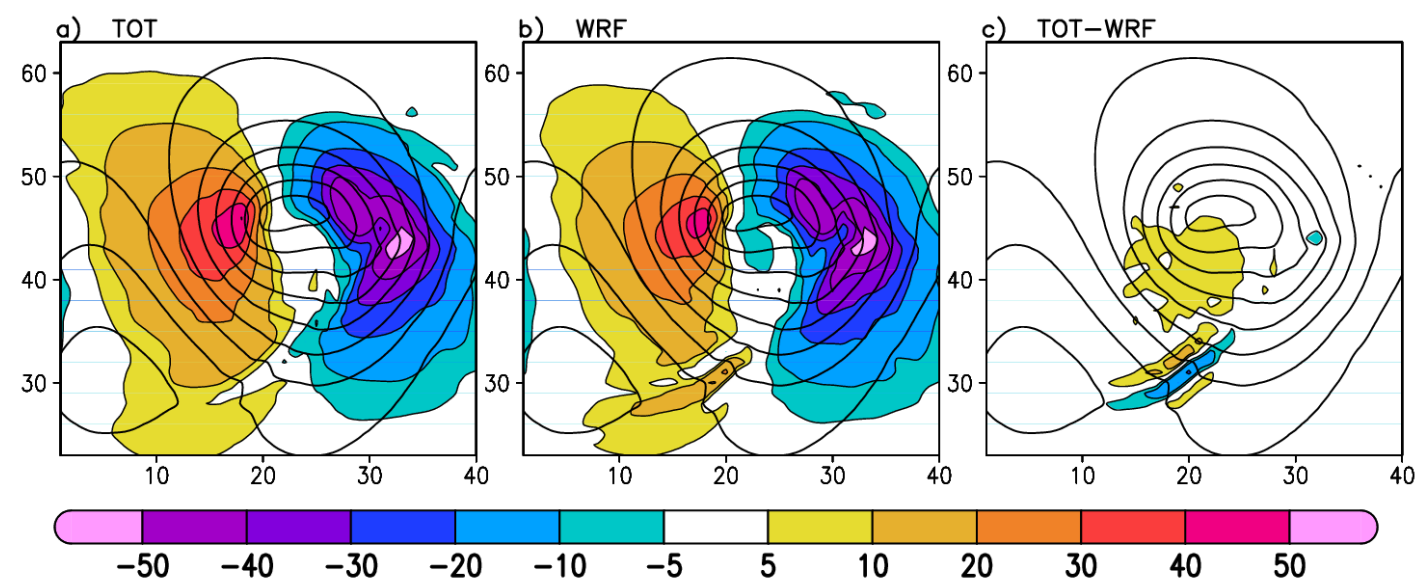

Figure S8: As Fig. S6, but for the height tendency at $900 \mathrm{hPa}$. Unit is $m h^{-1}$. Compare with Fig. 6 in the main paper. 

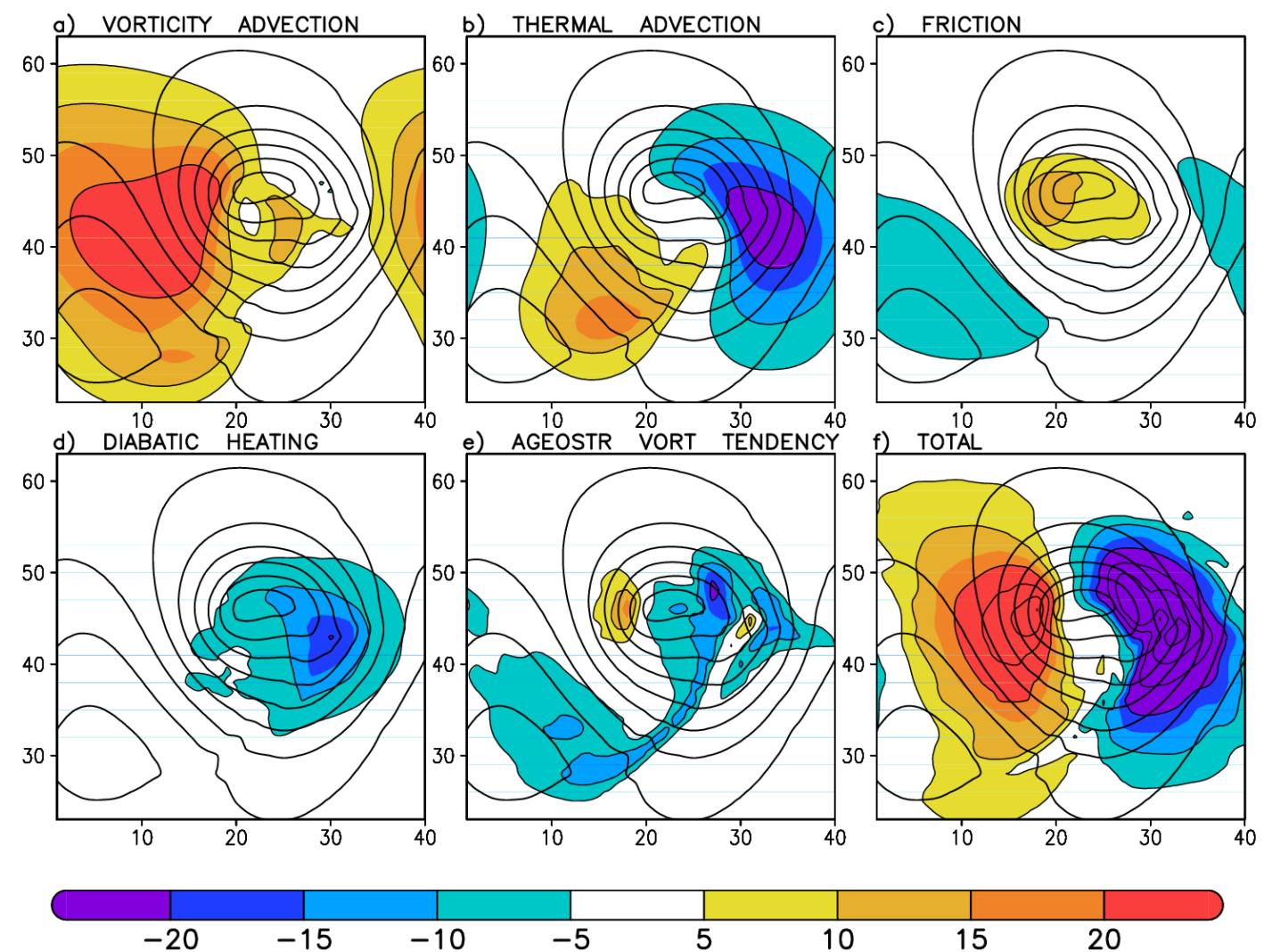

Figure S9: As Fig. S7, but for height tendency components at $900 \mathrm{hPa}$ level. Unit is $m h^{-1}$. Note that the color scale of $\mathrm{f}$ ) differs from Fig. S8a. Compare with Fig. 8 in the main paper.

\section{References}

Willison, J., Robinson, W. A., and Lackmann, G. M.: The importance of resolving mesoscale latent heating in the North Atlantic storm track, J. Atmos. Sci., 70, 2234-2250, 2013. 